\title{
Welcome to Silence
}

\author{
David C Baulcombe ${ }^{\dagger}$ and Phillip D Zamore*t
}

\section{Editorial}

Welcome to Silence [1], a new open-access journal devoted to RNA silencing and other pathways directed by non-coding RNAs. Silence springs from the extraordinary, yet brief, history of RNA silencing. In just two decades, we have seen the anomalous properties of plant and fungal transgenes connect with a series of amazing experiments in which injected double-stranded RNA triggered silencing in worms. These diverse lines of research revealed the essence of RNA interference (RNAi), and the importance of these discoveries has been recognized through numerous awards and accolades including a Nobel Prize for Fire and Mello $[2,3]$.

Our current understanding of RNA silencing derives from experiments performed in organisms from three kingdoms, experiments that directly inspired billion-dollar investments by biotechnology and pharmaceutical companies to use RNA-silencing both to diagnose and to treat disease in humans. Both small interfering RNAs and microRNAblocking antisense oligonucleotides are now in human clinical trials [4]. Some of the first GM plants to be produced exploited RNA silencing, although the mechanisms were not well understood at the time $[5,6]$. The study of RNA silencing produced enabling technology that allows each gene in a sequenced genome--even cultured human cells--to be knocked out or knocked down, providing a lifeline to functional genomics. There can be no question that RNA silencing research has had an impact!

RNA silencing has excited scientists and non-scientists alike: witness front-page headlines in the American and British press [7-10], even before the Nobel Prize. Such interest, of course, reflects the power of RNA silencing as biotechnology. But equally important is that RNA silencing exemplifies the elegant creativity of natural selection. Just as we might gaze in awe at a blue whale in the ocean (how

\footnotetext{
* Correspondence: phillip.zamore@umassmed.edu

+ Contributed equally

'Editors-in-Chief, Silence, BioMed Central, London, UK
}

can such a creature exist?), we marvel at the simple principles and complex molecular machines that underlie RNA silencing pathways. The role of silencing as an antiviral defence in plants and invertebrates illustrates this point: it uses the sequence of the invading virus itself to define the targets to be repressed and so has infinite specificity [11]. As a defense system RNA silencing is unsurpassed.

The study of RNA silencing has now travelled far from its posttranscriptional roots. The link between RNA and epigenetic silencing by chromatin modification, for example, is well established in many organisms [12]. In other developments the discovery of novel families of small silencing RNAs continues to expand the universe of guides far beyond the original microRNA and small interfering RNA pioneers [13]. This diversity is not mere molecular icing on the RNAi cake, because silencing underpins biological phenomena as diverse as virus resistance, control of chromosome architecture, transposon activity, genome rearrangement, and development, as well as responses to biotic and abiotic stimuli [14].

In parallel, other types of RNA-mediated mechanisms have been discovered, from CRISP RNAs [15] in bacteria to unexpectedly large families of non-coding RNAs derived from the intergenic regions of animals and plants [16]. These discoveries have been informed by, and in turn enrich the intellectual framework of RNAi. Thus, Silence will enthusiastically publish papers on these and other RNAbased mechanisms in addition to studies of the canonical RNA silencing pathways.

Papers with (RNA) AND (silence OR silencing) in their titles or abstracts first appeared in the mid 1990s; there are now more than 1,400 each year and the trend is increasing (source: Web of Science) [17]. So why introduce a new journal if these papers are already finding a home? Two answers explain our motivation in founding Silence. First, the history of silencing is one of extensive cross-fertilization among different research communities. Such interorganism as well as inter-disciplinary collaboration and discussion explains the remarkable productivity of our field.

(c) 2010 Baulcombe and Zamore; licensee BioMed Central Ltd. This is an Open Access article distributed under the terms of the Creative 
Unfortunately, the expansion and diversification of RNA silencing research threatens to fragment our intellectual community. Increasingly, the opportunity for a plant researcher, for example, to read a paper on genomic rearrangements in protozoa or for a fly geneticist to learn of the discovery of a novel mechanism of transposon control in fungi is being lost. Of course, existing journals devoted to the study of RNA will always publish some RNA silencing papers, but it is unreasonable to think that these journals can allocate a high proportion of their pages to our field. As RNA silencing research diversifies, we risk losing the excitement generated by the common enthusiasm for RNA silencing that unites distinct research communities. Silence seeks to nurture that enthusiasm by sustaining the interdisciplinary flavor of our field.

Second, Silence is a response to the rise of genomics and high throughput sequencing. These developments challenge molecular biologists because they demand a new, computational outlook on biological data. There is an enormous opportunity for bioinformaticians, mathematicians and statisticians to work together with experimental biologists to meet this challenge. They will extract useful and interesting information from genome sequences and large datasets and integrate them with similarly large datasets dealing with various other "omic" analyses of experimental systems. Modeling as a basis for hypothesis generation and testing will become increasingly important.

Silence can help molecular biologists and geneticists communicate effectively with computational scientists. We would be pleased, for example, to publish computational tools and research papers that use "dry science" to investigate RNA silencing or non-coding RNAs. We welcome reviews and commentaries in which computationalists introduce novel ideas, approaches and concepts in a style that is accessible to experimentalists.

This inaugural issue of Silence presents a selection of articles on different topics and an insightful review to illustrate the type of paper that we would like to include as the journal grows. Our renowned and diverse editorial advisory board [18] ensures fair but rigorous peer review, and our open access publication pipeline provides an efficient and easy-to-use system run by the well established BMC team. All BioMed Central journals are included in PubMed Central [19] and other freely accessible full-text repositories. This complies with the open access policies [20] of many funders including those of the Howard Hughes Medical Institute, NIH, and Wellcome Trust [21-23].

We look forward to receiving your manuscripts for publication and your feedback about the journal. Silence is meant to be yours; your comments and submissions will ensure it succeeds as the hub of the RNA silencing field.
Received: 30 December 2009 Accepted: 12 January 2010

Published: 12 January 2010

\section{References}

1. Silence [http://www.silencejournal.com]

2. Fire A, Xu S, Montgomery MK, Kostas SA, Driver SE, Mello CC: Potent and specific genetic interference by double-stranded RNA in Caenorhabditis elegans. Nature 1998, 391:806-811.

3. Parrish S, Fleenor J, Xu S, Mello C, Fire A: Functional anatomy of a dsRNA trigger: differential requirement for the two trigger strands in RNA interference. Mol Cell 2000, 6:1077-87

4. Check E: RNA therapy beckons as firms prepare for clinical trials. Nature 2004, 429:792

5. Napoli C, Lemieux C, Jorgensen R: Introduction of a chimeric chalcone synthase gene into petunia results in reversible co-suppression of homologous genes in trans. Plant Cell 1990, 2:279-289.

6. Lindbo JA, Silva-Rosales L, Proebsting WM, Dougherty WG: Induction of a Highly Specific Antiviral State in Transgenic Plants: Implications for Regulation of Gene Expression and Virus Resistance. Plant Cell 1993, 5:1749-1759.

7. The Economist "Discovering what genes do. Shooting the messenger: A new way to detect the jobs done by individual genes works in mammals," 2001 [http://www.economist.com/sciencetechnology/ displaystory.cfm?story id=E1 GPDRGS].

8. The Economist "Oncology: Nanotechnology cures cancer!" 2005 [http:// www.economist.com/sciencetechnology/ displaystory.cfm?story id=E1 PJPVJDS].

9. The Economist "BRIEFING: RNA-based drugs. Little hopes: New classes of drugs that exploit the new RNAs are in development," 2007 [http:// www.economist.com/sciencetechnology/ displaystory.cfm?story id=E1 JPPPQRN].

10. Regalado A: "Genetic Switch: Turning Off Genes Sheds New Light On How They Work,". Wall Street Journal 2002, CCXL(26):

11. Baulcombe DC: Fast forward genetics based on virus-induced gene silencing. Curr Opin Plant Biol 1999, 2:109-13.

12. Kavi H, Birchler J: Interaction of RNA polymerase II and the small RNA machinery affects heterochromatic silencing in Drosophila. Epigenetics \& Chromatin 2009, 2:15.

13. Kim VN: Small RNAs just got bigger: Piwi-interacting RNAs (piRNAs) in mammalian testes. Genes Dev 2006, 20:1993-7.

14. Zamore PD, Haley B: Ribo-gnome: The big world of small RNAs. Silence 2005, 309:1519-1524.

15. Oost J van der, Brouns SJ: RNAi: prokaryotes get in on the act. Cell 2009, 139:863-865.

16. Jacquier A: The complex eukaryotic transcriptome: unexpected pervasive transcription and novel small RNAs. Nature Reviews Genetics 2009, 10:833-844.

17. Web of Science [http://wok.mimas.ac.uk/

18. Silence Editorial Board [http://www.silencejournal.com/edboard]

19. PubMed Central [http://www.pubmedcentral.nih.gov/]

20. BMC Open Access Policies [http://www.biomedcentral.com/info/ authors/funderpolicies/

21. HHMI [http://www.hhmi.org/about/research/journals/ main?action=search]

22. NIH [http://publicaccess.nih.gov/

23. Wellcome Trust [http://www.wellcome.ac.uk/node3302.html]

doi: 10.1186/1758-907X-1-1

Cite this article as: Baulcombe and Zamore, Welcome to Silence Silence 2010, 1:1 